\title{
La nostalgia prístina y la vulnerabilidad de las trabajadoras domésticas en Roma, de Alfonso Cuarón
}

\section{THE PRISTINE NOSTALGIA AND THE VULNERABILITY OF DOMESTIC WORKERS IN ROMA, BY ALFONSO CUARÓN}

\author{
Martin Camps \\ University of the Pacific \\ mcamps@pacific.edu
}

\begin{abstract}
Alfonso Cuarón calificó a Roma (2018) como "su primera película". Filmada en blanco y negro, narra la historia de Cleo, una trabajadora doméstica en una casa de la colonia Roma, donde trabaja para una familia de clase media que está pasando por el divorcio de los padres. Cleo se embaraza de un hombre que la desprecia. La familia también es testigo de la represión del gobierno en el llamado "Halconazo" de 1971. Me interesa la película no solo por la belleza estética en la cuidadosa reconstrucción de una memoria, sino también por exhibir la jerarquía de clases y las estructuras de dominación hacia las empleadas indígenas que huyen de la pobreza y el atraso rural como resultado de un Estado desinteresado en las comunidades minoritarias.
\end{abstract}

PALABRAS CLAVE: memoria, clases sociales, estética y política, dominación, comunidades indígenas
Alfonso Cuarón described Roma (2018) as "his first film". Filmed in black and white, it tells the story of Cleo, a domestic worker in a house in the "Roma" neighborhood where she works for a middle-class family that is going through the divorce of their parents. Cleo becomes pregnant with a man who despises her. The family also witnesses the government's repression in the so-called "Halconazo" of 1971. I am interested in the film not only for the aesthetic beauty in the careful reconstruction of a memory, but also for exhibiting the class hierarchy and the structures of domination towards indigenous female employees fleeing poverty and rural backwardness as a result of a disinterested Mexican government in their own minority communities.

KEYWORDS: memory, social classes, esthetics and politics, domination, indigenous communities 


\section{DIVERSIDAD EN LA PANTALLA GRANDE}

El cine con la presencia de pueblos originarios ha tenido un momento de auge en las últimas décadas. En el Perú, por ejemplo, el contraste de la ciudad y la serranía está presente en las cintas de Claudia Llosa Madeinusa (2006) y La teta asustada (2009), ambas con la notable Magaly Solier. Recientemente la película Retablo (2017), de Álvaro DelgadoAparicio, relata un aspecto poco tratado en el cine de tema indígena: la homosexualidad y la represión por parte de sociedades patriarcales, tema similar a la película mexicana Sueño en otro idioma (2017), de Ernesto Contreras, donde se explora la relación de dos hombres que son los últimos hablantes de una lengua original y que, además, comparten un secreto de juventud. La película El abrazo de la serpiente (2015), de Ciro Guerra, así como Pájaros de verano (2018), giran alrededor de una planta (la yakruna y la marihuana) en el contexto colombiano. En Guatemala, Ixcanul (2015), de Jayro Bustamente, narra las privaciones de una adolescente en una montaña y la migración hacia el "otro lado del volcán" como única opción de sobrevivencia al matrimonio por arreglo.

En el contexto mexicano, Tío Yim (2018), de Luna Marán, realiza un cuadro personal sobre el pensador y trovador zapoteco Jaime Luna relatado por el lente amoroso de su hija sobre la importancia de la conservación de la naturaleza. Sin embargo, El ombligo de Guie'dani (2018), del director Xavi Sala, toca directamente el tema de Roma con respecto a una adolescente indígena que se rehúsa a aceptar el rol de trabajadora doméstica impuesto por su madre. La muchacha se rebela ante el clasismo y en un momento crucial de la película organiza una fiesta con una amiga en la casa de sus empleadores cuando se han ausentado por un viaje y ella se ha quedado a cargo. Por supuesto, este no es un recuento exhaustivo de la producción fílmica con tema indígena, pero provee un contexto a la película de Cuarón. Por supuesto, si hacemos espeleología de las primeras cintas de tema indígena en México habría que remontarnos a Cuauhtémoc (1904), de Carlos Mongrand, o El suplicio de Cuauhtémoc (1910), de Manuel Cirerol y Carlos Martínez Arredondo; o a películas como María Candelaria (1944), de Emilio Fernández, Tarahumara: cada vez más lejos (1965), de Luis Alcoriza, o Tizoc (1957), de Ismael Rodríguez. Sin embargo, las cintas de las últimas dos décadas representan un avance significativo en calidad y temas sobre la cosmovisión indígena, lo que habla de un interés multicultural por la diversidad lingüística y que sale de los patrones comunes que giraban en torno a la ciudad latinoamericana, esto es, la mestizofilia (Chorba, 2007) o la vida criolla como modelo racial de la "modernidad" latinoamericana, una suerte de calco norteamericano.

\section{TODOS LOS CAMINOS LLEVAN A ROMA}

En el documental Road to Roma (2020), Cuarón permite inspeccionar lo que él describe como la "plomería" de su multipremiada película, su primera cinta en México después de dos décadas de ausencia, que con una sutil línea argumental va construyendo la imagen 
prístina de la memoria de su familia en la Ciudad de México en la década de los setenta, como dice en sus propias palabras en entrevista a Valdés (2018): "A kind of spiritual X-ray of my family, with its wounds and its sores". Cuarón no escatima recursos en la reconstrucción de época en la calle Insurgentes, los aparadores de tiendas con vestidos, fachadas del banco Serfín para un trávelin donde el personaje, Cleo (Yalitza Aparicio), se subsume en esas calles llovidas y plagadas de vendedores, tráfico y peatones. Cuarón dice que el contexto es tan importante como el personaje; por eso, prefiere no usar los close-ups característicos de los programas de la televisión que se centran en el hablante, sino situar a los personajes en el espacio donde están hablando.

Esos trávelin de Roma son la arquitectura de la cinta misma, el deambular de una familia en una ciudad que acababa de salir del garrotazo de la represión social en 1968 y estaba por enfrentar el Halconazo de 1971. Cuarón se basa en fotografías de la época para reconstruir milimétricamente imágenes emblemáticas que vio en los periódicos que narraban la trifulca y ocultó computacionalmente los visos de la modernidad (como las omnipresentes antenas de satélite salpicadas en los techos). El lente se enfoca en una mueblería, desde donde posiciona a sus personajes para atestiguar desde las ventanas panorámicas el ataque que sucedió en las calles.

Cuarón describe el desgaste emocional que significó recrear el cuadro nostálgico de la infancia. Por ejemplo, expresa el "mal humor" que sentía hacia el personaje que interpreta a su papá Antonio (Fernando Grediaga), pero descubre que su frustración se debe a que está dirigiendo la figura de un hombre al que juzgó por abandonar a su familia. La arqueología reconstructiva de la película cumple la función de una cinta ambientada en una época, además de encontrar la veta de una memoria dolorosa en su biografía personal y su intersección con el trauma nacional por la represión del Estado. Cuarón tuvo la oportunidad de recrear un diorama de su infancia en tamaño real y con presupuesto de estudio fílmico, pero esta espeleología psicológica arroja también una crítica a cómo su familia y la sociedad mexicana conviven con las empleadas domésticas que suplen la ausencia de los padres y se convierten en las dispensadoras de ternura para los hijos ajenos. El acercamiento de Cuarón a Roma es una forma de cauterizar su pasado a partir de la mirada de Cleo, como expresa en esta entrevista a James (2019):

\footnotetext{
The only way to approach memory is from the standpoint of the present. Inevitably, it's going to be tainted by the prism of present interpretation. Probably, if I had done this at another stage in life, it would have been more nostalgic, romanticized and subjective. I was not interested in that because I wanted to come to terms with my own past, where everything is seen through the very specific character of Cleo. (p. 58)
}

Otro ejemplo del trabajo reconstructivo es la remodelación del hospital que estaba a punto de ser derruido y la producción reconfiguró el piso, los lavabos y otra utilería del 
nosocomio para crear el escenario donde toma lugar el momento clave en la historia, cuando Cleo se da cuenta de que su hija nació muerta. Cuarón relata que los doctores y enfermeras eran todos profesionales de la salud y ejercieron según lo que indica su quehacer científico. Yalitza Aparicio no sabía tampoco que el bebé nacería muerto en la línea del libreto y vemos su reacción visceral ante un evento desastroso.

En Cuarón tenemos, entonces, a un director meticuloso con una imagen clara de lo que desea ver en el cuadro y un perfeccionismo que le lleva a hacer sesenta y dos tomas para lograr la secuencia exacta, por ejemplo, aquella cuando un grupo de hombres dispara las armas en el día de campo en el momento exacto en que unos perros cruzan el cuadro. Cuarón explica a una de las actrices que no debe decir la expresión "qué onda" porque todavía no se usaba'.

Cuarón explica en este documental apendicular que la figura de la nana, a quien le dedica la película, estuvo basada en Liboria Rodríguez, originaria de Tepelmeme, Oaxaca. "Libo" aparece en Y tu mamá también (2001) durante el viaje a la playa, cuando Julio (Gael García Bernal) y Tenoch (Diego Luna) se detienen en el pueblo donde nació la niñera y la voz en off recuerda este dato que parece accesorio en ese momento, pero es la semilla del universo de Cuarón². En efecto, escribe Teodoro (2018): “There are plenty of Mexican films more daring, innovative, and politicized, but part of the value of Cuarón's more mainstream Mexican films lies in their ability to honor under-recognized characters like Cleo with the largest stage possible" (p. 35). El director explica que su nana creció con muchas carencias e iba a las funciones de cine a ver cualquier película que exhibieran. Cuarón describe la comunicación que había entre ellos y la separación de clases sociales que divide a indígenas, mestizos y criollos en la sociedad mexicana. Para Roma, por ejemplo, la producción elaboró un sofisticado álbum fotográfico de los extras que participarían dividido por clases sociales y etnicidad para que aparecieran combinados en las distintas tomas, en una suerte de arreglo plástico de la diversidad étnica en el México de los setenta. Esto parece una exuberancia de composición, pero también evoca la composición estética de un cuadro de castas del siglo XVII.

\section{LA SELVA DE CONCRETO}

La película inicia con una toma enfocada en el piso de la cochera, y escuchamos el trabajo de Cleo que arroja unos cubetazos en el patio de la casa de la calle Tepeji 21, esquina con

1 Sin embargo, es una de las expresiones clave de esa época, que inauguró toda una literatura precisamente llamada literatura de la Onda, que recogía esa época sesentera de movimientos y descontento social.

2 Cuarón dirigió un cortometraje para Hora marcada en la televisión mexicana, un programa donde aprendió a pulso los tejemanejes del cine. En el episodio No retornable aparece la casa y la fachada de Tepeji 21. 
Monterde. En el reflejo vemos un avión que cruza el cielo. Cuarón explica que quiso iniciar con el suelo y terminar en el cielo, cuando Cleo asciende las escaleras en su lugar de trabajo y también de esparcimiento. Los aviones significan una realidad para los capitalinos, representan el trasiego de personas. Pero el agua enjabonada en los mosaicos refleja el resultado de la labor de Cleo, que está muy alejada de los lujos de un viaje en avión porque su función es la terrestre tarea de limpiar la mierda del perro. El sonido del agua se conecta también con el final de la película en el mar veracruzano y la coronación de su sacrificio por la familia. Escuchamos el sonido del drenaje tragándose el agua y la toma se abre para introducirnos al personaje de Cleo clareando el desecho del perro antes de que llegue el "señor". Vemos a Cleo inmersa en sus rutinas diarias, ir al baño, descargar el agua del retrete. Luego tenemos la casa, que para ella no es el lugar de la nostalgia que recrea Cuarón, sino su lugar de labor. Para la familia, es su espacio íntimo y Cleo es la empleada doméstica que se ha adaptado como otro miembro de la familia. Cleo se comunica con su compañera, Adela (Nancy García), en lenguaje mixteco como una manera de entablar distancia con la familia y construir una isla lingüística a salvo de la visión de "otredad" marcada por la diferencia de clase social. Por ejemplo, después de que Cleo recoge al niño, el muchacho le pide que "no hablen así". El lenguaje mixteco tiene medio millón de hablantes, cerca de 81 variantes y es una de las 68 lenguas que se hablan en México, según el INALI (Instituto Nacional de las Lenguas Indígenas). Que el niño le ordene no usar ese lenguaje denota la prohibición de usar una lengua autóctona que contradice la versión mestizofílica de un país homogeneizado, la "raza de bronce" definida por José Vasconcelos. Carrie Chorba ha estudiado este lento proceso de apertura del lente homogeneizante en su libro Mexico, from Mestizo to Multicultural (2007). Un punto nodal del despertar hacia una cultura más inclusiva fue la rebelión del Ejército Zapatista de Liberación Nacional (EZLN) que en 1994 atrajo la atención sobre el desplazamiento injusto de los pueblos originarios del proyecto neoliberal mexicano.

Roma no cuenta con un score o tema musical porque los sonidos de la ciudad (perros ladrando, vendedores) se convierten en el escenario auditivo de la película. A lo largo de la cinta, escuchamos los rumores de los vendedores ambulantes de la ciudad que venden miel de colmena, así como canciones populares como "Sombras nada más" o temas de cantautores populares como Juan Gabriel que escuchamos de fondo en la estación Radio Variedades. Roma es una caja de resonancia de la memoria de una infancia cuando los sonidos actúan como una caja musical de recuerdos. Tal como los sonidos presentan la textura de la ciudad, el director presta atención a objetos que añaden profundidad al tiempo histórico y los momentos de la nostalgia. Por ejemplo, vemos a un mono de lucha libre de plástico y un balón ponchado, los libros del Tesoro de la juventud que eran parte de toda biblioteca hogareña de la clase media mexicana. El lavadero en la azotea, donde hay un primer momento tierno de la relación creciente entre Cleo y el niño: Cleo se acuesta solidariamente con el niño en una losa de concreto y dice: "Me gusta estar muerta", entre 
la ropa secándose en el tendedero, en un momento afectivo de una relación naciente. La azotea es el espacio de Cleo, sube a su cuarto por las escaleras de metal donde comparte estancia con Adela; la abuela "cuida que no gasten la luz" —recordándoles su condición de empleadas-y ambas hacen ejercicio para "bajar los tamales" iluminadas con velas.

Cleo y Adela se apresuran por las calles hasta llegar a la Casa del Pavo (restaurante emblemático de la culinaria chilanga) y en la televisión ven al Profesor Zovek (escapista e hipnólogo popular en los sesenta y muerto en un accidente de helicóptero en 1972) empujando un camión con los dientes, mientras en los anuncios aparece el candidato del Partido Revolucionario Institucional (PRI), Luis Echeverría, el "tapado" (llamado así por la costumbre de ser elegido antidemocráticamente o por "dedazo") del sistema priista al que Vargas Llosa llamó justamente "la dictadura perfecta". Allí se ven por primera vez Cleo y Fermín (Jorge Antonio Guerrero); al salir del lugar, Fermín se toma lo que resta de una botella de Coca-Cola para exhibir su falta de recursos. En la entrada del cine vemos a un vendedor de globos y pelotas. La siguiente escena es Fermín y Cleo en un hotel de paso; él aparece desnudo haciendo movimientos estilizados de artes marciales con un fuste. Fermín expresa que tenía muchas carencias y que había caído en el "chemo" (droga) y encontró en las artes marciales una dirección, aunque sabremos más adelante que está sirviendo al Estado mexicano para reprimir al sector social pauperizado del que intentaba escapar. Es decir, el que podría ser el amor de Cleo se convierte en su abusador.

En la siguiente escena, Cleo aparece dándose un baño; después, despierta a los niños con mucha ternura, con besos y cosquillas. Se escuchan las rutinas de la mañana, los sonidos de la campana del servicio de recolección de basura. Prepara el desayuno, un huevo tibio a Pepe (Marco Graf) que representa a Cuarón de niño, y la avena para el doctor. Al final del día llega Antonio, el "señor", a tomar posesión de la casa limpia, en su auto, escuchando música clásica. El doctor trabaja en el Instituto Mexicano del Seguro Social (IMSS) y estaciona el auto Ford Galaxie en el garaje con una precisión milimétrica. La familia se sienta frente al televisor a ver un programa vespertino, Los polivoces (programa sesentero de sátira). Cleo también se sienta por un minuto a disfrutar del programa de televisión, pero tiene que levantarse tan pronto se acomoda para traer "un té de manzanilla para el señor". Los espacios están marcados por la clase y la posición económica, y también por el lenguaje. El patriarca, quien se molesta por la "caca de perro" en sus zapatos. El día termina con Cleo lavando los platos en la cocina.

Sofía explica a los hijos que el "señor Antonio" irá a una conferencia en el extranjero. Frente a la casa hay una despedida de la pareja con aire de separación matrimonial definitiva. Ella le dice: "Aquí estaremos" y abraza por la espalda el cuerpo tenso del marido, como un gesto desesperado de intentar atajar lo inevitable. Aparece en la calle una banda de guerra escolar que marca el inicio de la soledad para ella y el fin simbólico de 
su matrimonio. La "señora" se enoja con Cleo por las cacas del perro, tal vez como una razón absurda de que el doctor se vaya de la casa. Cleo se convierte también en el paño de lágrimas y el desfogue de las frustraciones de Sofía.

En la segunda vez que aparece el interior de un cine, Fermín y Cleo están viendo una película de la Segunda Guerra Mundial, La Grande Vadrouille (1966). Cleo le expresa a Fermín que "está con encargo" e inmediatamente Fermín dice que va al baño, pero no regresa y olvida su chaqueta en el asiento. Se termina la película (a la que los asistentes del cine responden con aplausos, una práctica ahora en desuso, pero añade un acento a la nostalgia cuaroniana). Cleo espera el regreso del novio en los escalones del cine. En otra escena de los rituales de la ciudad, la película captura una tarde de granizo y vemos a los niños jugando en el patio cantando "que llueva, que llueva". Cleo aparece ensimismada mirando la lluvia desde la cocina. Se acerca la Navidad y la señora está atravesando por el divorcio, pero mantiene la farsa de que el padre está en Canadá y les pide a sus hijos que le escriban una carta para que no se olvide de ellos.

Cleo explica a su patrona que está con encargo y le pide que no la despida; ella responde: "Ay, mensa, cómo crees" y deciden ayudarla. Llevan a Cleo al hospital donde oímos finalmente el nombre completo de ella: Cleodegaria Gutiérrez. En el hospital ocurre un temblor mientras contemplaban a los niños en la incubadora, como un presagio de lo que ocurrirá después al perder a su bebé y como un guiño al terremoto de 1985 que terminaría de fracturar a la sociedad mexicana, para darse cuenta de que el gobierno priista era incapaz de ayudar a su pueblo y la sociedad civil tenía que darse manos a la obra para rescatar a sus seres queridos de entre los escombros. Después de la represión de 1968 contra los estudiantes en la plaza de las Tres Culturas en Tlatelolco y del Halconazo de 1971, el terremoto de 1985 sería el cisma que despertaría al pueblo mexicano del sopor de un partido hegemónico y desembocaría en la democracia incipiente del año 2000 con la elección de Vicente Fox como primer presidente electo de la oposición.

La familia pasa un fin de semana con los Richards para celebrar la Navidad. La casa muestra las disparidades económicas en México. En la sala se exhiben animales disecados, copas de vino en las mesas al lado de biberones para niños, un árbol de Navidad boyante de regalos y numerosa servidumbre. Daniela Rossell, en su libro de fotografías Ricas y famosas: México 1994-2001 (2002), deja constancia de la afición de la clase alta mexicana por los animales disecados en las salas exuberantes de sus casas y retrata también las legiones de empleados, jardineros, niñeras y mucamas que sirven a los patrones siguiendo la escala del color como en un cuadro de castas. En la película, los dueños de la casona disparan sus armas, son todos blancos y algunos hablan inglés, como una nota del poderío extranjero del capital mexicano. Hay un niño que juega con un traje de astronauta, como un alter ego del director que atesora sueños que trascienden esos espacios o un guiño a su cinta Gravity (2013). La casa muestra los excesos de una oligarquía, por ejemplo, embalsamar a todos los perros que han tenido en la estancia. 
Cleo escucha de una de sus colegas que uno de los perros fue envenenado por un conflicto con los "terrenos". Cleo baja a un primer piso donde celebran los trabajadores con música de "Corazón de melón" en un sitio donde sirven pulque y a Cleo se le cae un jarro con la bebida (un sonido seco como de piñata derrotada) como otro presagio del embarazo fallido, aunque ella no quería tomar alcohol para proteger al bebé. En otra escena, Cleo observa cómo la señora Sofía (Marina de Tavira) decide detener los avances seductores de Billy, que la "quería consolar" por su reciente separación. Cleo es la testigo de los eventos importantes de la familia, así como la familia se convierte también en la aliada en sus malas fortunas.

Esa noche habrá un incendio provocado por el conflicto de los terrenos referido antes. Todos acuden a apagar el fuego, aun los niños que lo toman como diversión. La quemazón del bosque parece un preludio del movimiento social que está por iniciar, el electrizante ambiente político que se cocinaba en el México de entonces. Aparece un hombre disfrazado como un monstruo (Krampus) que canta en nynorsk (noruego) mientras el bosque se incendia (véase Tovar, 2018). Al otro día salen a caminar por el campo y Cleo dice que le recuerda a su pueblo: "Así suenan los animales y así huele", dice. Es la memoria del pueblo que ella dejó para trabajar en la ciudad y por cuya labor ahora regresa a contemplar el campo abandonado, que paradójicamente está también bajo el poderío de la clase pudiente.

De regreso a la ciudad hay otro trávelin de una caminata nocturna en la ciudad: aparece el cine Las Américas, el banco Serfín, merolicos, vendedores perorando para vender cachitos de lotería, y vemos por segunda vez al señor Antonio, ahora de la mano de una mujer joven, y los amigos de los niños le dicen que han visto al padre con otra mujer. Vemos la escena recreada de una película de astronautas como otro guiño a su película Gravity. De hecho, en el cuarto de Pepe (Marco Graf), hay dibujos de astronautas y naves espaciales como corresponde a un chico de su edad y posición social. El auto es también un Ford Galaxie en referencia a las galaxias. De Cleo, en oposición, no sabemos cuál es su sueño, su aspiración; solo sabemos de las rutinas de su trabajo entrelazadas con la historia de la familia, pero sus anhelos aparecen soterrados. ¿Querrá trabajar en Tepeji 21 hasta el final de sus días?

Cleo va en busca de Fermín a las afueras de la ciudad; en las paredes se aprecian carteles políticos de la era de Carlos Hank González. En las calles encharcadas vemos de nuevo a un niño jugando a ser astronauta, pero esta vez con una cubeta en la cabeza, como un contraste de la capacidad de imaginación de los niños que trasciende las clases sociales o las zonas de la ciudad. Ramón, el novio de su amiga, está ensayando con una banda de rock en un arrabal. Cleo encuentra a Fermín recibiendo entrenamiento para reprimir al pueblo. En el cerro dice: "LEA, Estado de México"; uno de los entrenadores tiene una sudadera con el escudo de West Point para demarcar la injerencia norteamericana en la represión, como ejercicio clandestino de la doctrina Monroe. Frente al pelotón 
aparece el Profesor Zovek con un reto para ellos: les dice que únicamente los grandes maestros en artes marciales son capaces de alzar las manos con los ojos cerrados y sostenerse con un pie flexionado. Cuando Zovek realiza esta posición, coincide con el paso de un avión sobre su cabeza. Les dice: “Querían que levantara un jet?”. Para lograr esa posición se requiere de un desarrollo mental y físico, explica. De los presentes, Cleo es la única capaz de hacer el acto, es la elegida. Cleo finalmente aborda a Fermín, le pregunta si el entrenamiento es para las olimpiadas (aunque las olimpiadas fueron en 1968 y se supone que están en 1971), pero él responde: "Algo así". Ella le dice que está embarazada, pero Fermín se molesta; le pide agresivamente que no lo vuelva a buscar y le impreca: "Pinche gata". Un epíteto denigrante a su trabajo como empleada doméstica, gata como sinónimo de sirvienta, un peyorativo que califica su condición servil y el estanco social de los indígenas en México, cuya única opción en el proyecto del Partido Revolucionario Institucional es la migración a las ciudades, olvidarse de sus lenguas originales y desear formar parte de una sociedad que no tiene lugar para ellos, ni para su fenotipo, lengua o cultura. Así la película presenta la violencia del Estado mexicano hacia sus ciudadanos, pero también la violencia social hacia sus minorías étnicas.

La desilusión de Cleo se entronca con la de Sofía, que participa del mismo problema: el abandono de hogar del progenitor de su familia. Los niños juegan con una pista de carritos eléctricos, uno de los regalos de Navidad. En el fondo escuchamos la canción "Aquel día en que te marchaste", de Los Ángeles Negros. Hay una pelea entre los niños y uno de ellos le tiró un objeto que atravesó el vidrio de la puerta. Vemos a la señora estacionar el auto de una manera atropellada, rayando las puertas y demoliendo parte de una pared de ladrillo. El auto como representación de la relación con el marido, el poderío de la carrocería masculina, que contrasta con la manera cuidadosa con la que Antonio metía el auto, impacientado por la caca del perro que puede dañar su coche, ahora es deformado por la mujer que abolla el símbolo del patriarcado de ocho cilindros. La señora está borracha y se entiende que es también el fin de su matrimonio. Le dice a Cleo: "Estamos solas, no importa lo que te digan los hombres, siempre estamos solas". Una frase lapidaria que explica uno de los temas centrales de la película, la solidaridad/ soledad femenina frente al abandono masculino.

La abuela, Cleo y los niños van a buscar una cuna a una tienda de muebles y desde las ventanas que dan a la calle pueden ver el conato de rebelión y la sangrienta represión del cuerpo de granaderos; los policías esperan órdenes y se desata la trifulca con palos. Allí encuentran de nuevo a Fermín que tiene un arma en la mano (además de una playera, irónicamente, con un corazón) y apunta hacia Cleo; antes le había dicho que si la volvía a ver la mataría a ella y a la criatura. En ese instante se le rompe la fuente a Cleo y deben ir al centro médico a toda velocidad en el tráfico infame de la Ciudad de México. La abuela reza ante las adversidades hasta que llegan al sanatorio, donde la abuela tiene que hacer un esfuerzo por recordar el apellido de Cleo, como una señal de su identidad 
borrada: es Cleo, la "muchacha", no una mujer con apellidos. A partir de aquí vemos el despliegue clínico de la atención médica, escuchamos sus quejidos y el lenguaje técnico de los doctores (según Cuarón, el lenguaje de un parto real) que hacen todo por salvar al bebé que posteriormente nace muerto. El lenguaje aséptico del perito en los desenlaces humanos: "Suspendemos maniobras. No escucho el corazón de su bebé. Tu bebé nació muerto. Es una niña. Despídete de ella. Dámela por favor, necesitamos prepararla. Lo sentimos mucho". Y vemos en otra camilla la preparación del cuerpo del bebé, le cubren su rostro. Cleo se desarma en llanto. El nombre de la bebé es como el suyo, Cleodegaria Gutiérrez; su deseo en la azotea de "estar muerta" se ha realizado trágicamente en su hija.

Regresan a Tepeji 21. Escuchamos los sonidos lánguidos del afilador de cuchillos que llenan la casa de los sonidos de nostalgia. Vemos el rostro preocupado de Cleo, que está sentada en una silla frente a una puerta abierta, intentando procesar lo que ha pasado. La señora anuncia que irán a Tuxpan en Veracruz y llevarán a Cleo. La familia se está reconstruyendo a partir de este viaje (como en $Y$ tu mamá también). En el mar, vemos a los niños bronceados después de un día de sol; uno de ellos lee la revista infantil Periquita (Nancy, creada por Ernie Bushmiller). En la cena la madre les confiesa la cruda realidad, que su padre no volverá a casa. Que el viaje fue una manera de darle espacio para que él regresara a recoger su ropa y sus libros, y explica que ella ahora trabajará en una editorial, porque con su enseñanza en la preparatoria no les alcanzará. El esposo no les manda dinero y dice que quiere ver a los hijos, pero "no sabe cuándo".

En el cierre de la cinta, los niños juegan en la playa (símbolo de redención y reinicio); la madre tiene que irse por un momento y deja a Cleo encargada, pero les dice que no se metan al mar porque Cleo no sabe nadar. Sin embargo, los niños se introducen al mar pese a las advertencias de Cleo, que tiene que arriesgar su vida para salvar a la niña. La familia se congrega en la arena y la niña dice: "Cleo me salvó" y todos se abrazan asustados (como una Pietà de la compasión familiar) ante la posibilidad de perder a la niña. En ese momento, Cleo les confiesa que ella "no quería que naciera" refiriéndose a su propia hija, que no la deseaba. La señora le dice: "Te queremos mucho, Cleo". En la siguiente toma vemos el regreso de Tuxpan por la ventana del auto Galaxie. Vemos en Cleo una mirada de satisfacción, con los niños dormidos en el regazo, tal vez porque ha logrado expresar su tormentoso deseo de no querer la bebé de Fermín y por haber salvado a la niña de su empleadora como un canje simbólico, posiblemente también porque se ha sellado así su pertenencia a la familia.

\section{LA LUCHA (DOMÉSTICA) DE CLASES}

Cuando la familia regresa a la casa notan la ausencia de libreros y la disposición de los muebles en los cuartos producto del divorcio. La madre promete que se irán de viaje "a Disney no, pero a la Selva Lacandona o a Oaxaca" señalando su nueva situación 
económica. Sin embargo, aunque acaban de llegar del viaje, le piden a Cleo que haga un licuado de plátano y "gansitos" (pastelillos de chocolate). La vemos subir las escaleras de metal a su cuarto en la azotea, al mismo tiempo que un avión surca el cielo. La película cierra con los sonidos del afilador de cuchillos y los ladridos de los perros. En el guion, el final se describe de una manera poética:

Cleo sale de la cocina cargando su montón de ropa sucia y cruza el minúsculo patio y comienza a subir por la escalera de metal que lleva a la azotea.

Sus pasos reverberan a lo largo de la esquelética estructura en un quejido metálico que hace ecos por el pequeño patio, despertando a los pájaros enjaulados.

Cleo llega al descanso frente a su cuarto y continúa su marcha hacia lo más alto. Un carro de camotes aúlla triste, a lo lejos.

Paso a paso, Cleo asciende.

Arriba, más allá de la azotea, el cielo es puro. (Cuarón, 2016, p. 141)

No hay una redención de Cleo o una transformación del personaje; la familia ha cambiado y la señora de la casa mira al futuro con optimismo, pero Cleo carga "su montón de ropa sucia" hacia la azotea, su lugar de trabajo. Cleo no asciende a un lugar distinto donde "el cielo es puro"; el personaje sube a lavar ropa, a proseguir su rutina diaria de trabajo. Sin embargo, la disparidad de clase sigue allí, no ascendió un solo escalón en la escala social. En cambio, extrafílmicamente, para la actriz Yalitza Aparicio sí hubo una modificación que continuó después de la cinta. Se filtraron comentarios racistas de personas del medio artístico en México que insinuaron una falta de talento en Aparicio, se generaron memes discriminatorios y crueles, se le criticó su presencia en el boato de los Premios Óscar, de codearse con la crema y nata de Hollywood. Además, reanimó la discusión laboral en México en torno a las trabajadoras domésticas para proveerles un salario digno y prestaciones de ley. La película exhibió la disparidad del sur local, para utilizar una variación del término sur global, el eufemismo contemporáneo para llamar a las regiones expoliadas del planeta. El sur mexicano es el sur local despojado, como mostró el movimiento del EZLN, estratégicamente desindustrializado y cuyas comunidades indígenas fueron desplazadas por una educación deficiente y un sistema de salud defectuoso, además de un racismo rampante.

Roma es el álbum de memorias de un cineasta que ejerce un inventario y reconstrucción minuciosos de ciertas imágenes que lo marcaron en su niñez en la colonia Roma en la Ciudad de México, pero también es el registro de la discriminación hacia los indígenas. En entrevista con Cine Premiere, Alfonso Cuarón expresó a Oliva (2018) que la película fue "una reconstrucción milimétrica, en donde hasta los cajones que no se abrían tenían adentro los elementos que tendrían que estar ahí" (p. 45). De los tres cineastas mexicanos que han probado suerte en Hollywood, Cuarón es el más poético e intimista. Así como Guillermo del Toro confecciona monstruos inauditos, o Alejandro González Iñárritu 
emula una acción épica de la mejor época del cine, Cuarón poetiza filosóficamente con sus películas.

Por ejemplo, en su cinta Solo con tu pareja (1991), donde aborda el tema del sida en una comedia de situación a la mexicana, o en la road movie Y tu mamá también (2001), discurre sobre el último viaje de una mujer enferma de cáncer en medio de un ménage à trois "charolastrero"; o en Gravity (2013) presenta la levedad humana en el espacio exterior a partir de la pérdida de un infante; o el fin del mundo que empieza en la esterilidad de los vientres maternos en Children of Men (2006). Roma aborda el trauma de un país por la represión social y el trauma personal de la pérdida de un bebé. Asimismo, revela el entarimado social que sigue los escalafones de raza y clase estipulada por las pirámides raciales de la colonia. A este respecto, Judith Rollins en su libro Between Women: Domestics and Their Employers (1985) estudia las jerarquías de clase y estructuras raciales de la división del trabajo en el contexto de trabajadoras afroamericanas, y los actos deferenciales que esperan quienes las emplean. Esta estructura de poder, de relaciones de dominación y jerarquización en el contexto colonial y hacendario mexicano hacia el indígena aparece en Roma como un sistema normalizado donde las empleadas domésticas son, por lo general, mujeres de estrato social bajo, de comunidades rurales y de un grupo étnico minoritario y despreciado. Escribe Rollins (1985): "While the types of economic systems that have institutionalized inequality have been varied, all have included interpersonal rituals that somehow reinforced the desire for accepting the systemic inequality of entire categories of people" (p. 6).

Me vienen a la mente tres películas que relatan las relaciones sociológicas de servicio incrustadas en la vida de una familia y el deseo de aceptar inequidades sistémicas. The Help (2011), de Tate Taylor, en el contexto del racismo norteamericano del sur, donde las sirvientas denuncian la discriminación de las familias blancas de Misisipi; La nana (2009), de Sebastián Silva, donde la niñera, que ha servido a una familia chilena "pituca" por dos décadas, sabotea a las nuevas trabajadoras del hogar; otra película es Babel (2006), de Alejandro González Iñárritu, donde en uno de los trípticos retrata la vida de una niñera en Estados Unidos que por azar del destino tiene que cruzar a los "güeritos" por el desierto de la frontera; la cuarta película sería El ombligo de Guie'dani (2018), que referí al inicio de este ensayo, donde una adolescente se niega a aceptar el rol de sirvienta que la sociedad le ha impuesto. Dos cuentos también con este tema son "Love Story", de Elena Poniatowska, donde desgrana la relación amor y odio de una "señora" (Teleca) con su sirvienta Lupe, que en un acto de represalia final le deja un redondo pedazo de mierda en la cama; y "Miss Amy" (en La frontera de cristal), de Carlos Fuentes, donde una adinerada mujer de Chicago se ensaña cruelmente contra su mucama de México; por ejemplo, le presta la casa para organizar una piñata para después correrlos y humillarla en medio de la celebración a punta de bastón. 
Roma es una obra de arte con muchas aristas. Se conecta a esa tradición de películas de la Ciudad de México que tiene como su fuente Los olvidados (1950), de Luis Buñuel, y Amores Perros (2000), de Alejandro González Iñárritu. La película de Buñuel describe la Ciudad de México durante el periodo del presidente Miguel Alemán y el crecimiento de la infraestructura que era inversamente proporcional al atraso social de la juventud. La escena final muestra a Pedro, el niño asesinado por El Jaibo, que es arrojado en el basurero como el cascajo residual de una ciudad/sociedad en construcción. Amores perros, medio siglo después, despliega la ciudad neoliberal donde persiste el atraso y una marcada diferencia de clases. En un triángulo de historias tenemos los dilemas morales de la clase alta, la rivalidad entre hermanos y un guerrillero que combatió al gobierno, pero ahora se alquila como matón. Roma añade otro capítulo a estas historias de la ciudad, desde la perspectiva de una familia que sufre un cambio radical, de igual forma que el país experimentó un descalabro radical por parte de la represión del gobierno ${ }^{3}$.

Roma es una película donde el cineasta recuerda cómo era la vida entonces en esa casa y al inspeccionar ese recuerdo también registra la condición de la empleada doméstica que participó en sus vidas por cuestiones económicas y eventualmente su labor "doméstica" se convirtió en un pilar de la memoria y la construcción de la infancia. La película también recrea el escenario sociopolítico en los setenta en México, la represión del jueves de Corpus y los halcones que acribillaron a los manifestantes. La película es una composición de la nostalgia de la infancia, de una Ciudad de México que no termina de mutar. La cámara se mueve con el personaje en trávelin por las calles donde se agolpan los anuncios de otra época.

\section{CONCLUSIÓN: LA VULNERABILIDAD DE LOS NO-CIUDADANOS}

Roma es una película de un metódico anticuario recolector de imágenes que exhibe los objetos ya idos: los autos, juguetes, programas de televisión que se han empolvado en un México de hace medio siglo. Los sonidos de la ciudad - como el afilador de cuchillos, el camotero, los merolicos-y el cine, el interior de aquellas salas de proyección engalanadas como iglesias del entretenimiento. Cuarón nos mete en su mundo de referencias, por ejemplo, estacionar el Galaxie en la cochera angosta, cuidar los ángulos, corregir cada centímetro para que entre sin un rasguño. Weintraub (2019) expresa esta permanencia del pasado, su prístina expresión en la claridad del presente:

3 Otra película memorable que relata la matanza de las Tres Culturas en Tlatelolco fue Rojo amanecer (1989), de Jorge Fons, y está narrada desde la perspectiva de una familia de clase media que presencia la matanza de estudiantes desde su apartamento. La película estuvo enlatada por unos años y logra una tensión dramática sin mostrar la masacre en sí. 
Memory, for the director, is not in itself an enigmatic patchwork of partial images that an artist must then re-interpret into some new aesthetic whole; it is, instead, an indelible trace of the past in the present, which the director is obliged to develop with the greatest possible clarity and exactitude.

Cuarón eligió bien al iluminar su película en blanco y negro. Si la película hubiera sido a color, habría parecido una reconstrucción histórica, pero el claror monocromático, los distintos tonos de gris, le imprimen el tono de la pincelada viva de una potente memoria personal que se queda en el espectador por mucho tiempo. En efecto, el director no intentó usar una imagen granular que diera la impresión de ser una reconstrucción del pasado, sino una versión actualizada de un momento, un trauma, al que se le han puesto varias capas de pintura, pero todavía sigue allí esa rotura.

Como hemos visto, en Roma también se trasmina la cuestión de la representación del indígena en el cine. El rostro de Yalitza Aparicio en la pantalla grande y su nominación al Óscar significó un salto importante para la actriz, pero también exhibió el colonialismo arraigado en México y la discriminación contra las "muchachas" o trabajadoras domésticas que en su mayoría son migrantes de comunidades indígenas que buscan trabajo en la ciudad. Utilizando el concepto de Bloom (2018) de noncitizens ${ }^{4}$ (el reconocimiento de las capacidades de los no-ciudadanos en un mundo de ciudadanos), podemos considerar la migración del interior del país como una relación de no-ciudadanos; las trabajadoras domésticas son difíciles de contabilizar con implicaciones adicionales para reconocer su vulnerabilidad.

A global estimate from 2010 suggests that there are at least 52,6 million domestic workers in the world, leading to the parallel observation that "[i]f all domestic workers worked in one country, this country would be the tenth largest employer worldwide". (Bloom, 2018, p. 173).

Su carácter migratorio, las barreras de lenguaje y la costumbre de cohabitar en las casas de los empleadores las pone en alto riesgo de vulnerabilidad. A ello se suma que laboran en condiciones de no reconocimiento estatal, lo que enraíza su vulnerabilidad en lugar de habilitarlas.

4 Bloom (2018) analiza la relación de no-ciudadanía con el Estado, que se extiende a comunidades migratorias, desplazadas y vulnerables. En efecto, las comunidades indígenas en México son ciudadanos, pero, como escribe Bloom, las minorías dentro del Estado pueden tener un estatus indeterminado o cuestionado: "There are those who lack citizenship where they live, though never having moved. This includes stateless persons, and minorities within a State whose status is disputed or undetermined. It includes formal citizens who suffer discrimination and exclusion, or who contest the State, and so are unable to make full use of their citizenships. Also included are people who relate to States from afar: the colonised, the conquered, and those with more subtle connections, resulting from global and multi- lateral systems, or global phenomena like climate change, for example" (p. 2). 
And it makes clear the levels of rightslessness of domestic workers. Cooking, cleaning and caring are vital to the healthy continuation of society and the claims made by domestic workers also form part of a wider struggle for recognition of these vital jobs, which have traditionally been seen as women's work in the States under consideration here. In this way, as well as through the wider discourse of care, the Domestic Workers Convention also helps to show potential interactions between noncitizenism and feminism. (Bloom, 2018, p. 177)

La aparición de Yalitza Aparicio, una mujer indígena en la pantalla grande, significó un cortocircuito a la normativa hegemonizada en la televisión mexicana, donde el fenotipo aceptado es la tez clara; donde en las telenovelas, programas de televisión, películas y series televisivas, las mujeres indígenas ocupan labores domésticas, trabajan en la cocina, visten atuendos serviles y figuran entre las sombras de las narrativas de personajes principales que se conforman al constructo de una sociedad que "aspira" a la tez clara. En efecto, "[l]a apropiación de medios tecnológicos de comunicación abre a los grupos indígenas las posibilidades de ser vistos y oídos por los consumidores de narrativas occidentalizadas que los han ignorado por siglos" (Nahmad Rodríguez, 2007, p. 125). El personaje de Cleo subrayó la ausencia de la representación indígena en el cine mexicano y evidenció el todavía vigente sistema de castas que en su triángulo de valor sitúa a los indígenas mexicanos en la base y los invisibiliza de roles importantes en el cine o los destina a papeles estereotípicos que perpetúan su condición subalterna. Al poner a un personaje indígena en el centro del filme, se avivaron discusiones urgentes sobre las comunidades minoritarias en México y avanzó la discusión de sus derechos laborales, el racismo soterrado y vulnerabilidad. Estará por verse si otros cineastas mexicanos continúan con esta visibilización (o su reciudadanización) del indígena, o siguen siendo relegados a pequeñas producciones de cine independiente, como vimos al inicio de este ensayo; la producción fílmica de las dos últimas décadas permite ver el futuro con relativo optimismo.

\section{REFERENCIAS}

Bloom, T. (2018). Noncitizenism: Recognising Noncitizen Capabilities in a World of Citizens. Routledge.

Clariond, A., y Nuncio, G. (Directores). (2020). Road to Roma. [Película]. Netflix Studios.

Cuarón, A. (2016). Roma [Guion]. https://deadline.com/wp-content/uploads/2018/12/ Roma-Screenplay-SPANISH.pdf

Cuarón, A. (Director). (2018a). Roma [Película]. Esperanto Filmoj; Participant Media. 
Cuarón, A.. (2018b). Roma. Assouline.

Chorba, C. (2007). Mexico, from Mestizo to Multicultural: National Identity and Recent Representations of the Conquest. Vanderbilt University Press.

James, N. (2019). Where the Heart. Sight \& Sound, 29(1-2), 56-62.

Nahmad Rodríguez, A. D. (2007). Las representaciones indígenas y la pugna por las imágenes. México y Bolivia a través del cine y el video. Latinoamérica, 45, 105-130.

Oliva, J. (2018). Alfonso Cuarón: el adiós a las inseguridades. Cine Premiere. https://reader. magzter.com/preview/o7fvaia1hsmqh4kc1mtynj3126490/312649\#page/8

Rollins, J. (1985). Between Women: Domestics and Their Employers. Temple UP.

Rossell, D. (2002). Ricas y famosas: México 1994-2001. Océano.

Teodoro, J. (2018). The Turning of the Earth. Film Comment, September-October, 32-35.

Tovar, E. (29 de diciembre del 2018). Nostalgia y misticismo vikingo en Roma de Cuarón. Cine Oculto. https://cineoculto.com/2018/12/nostalgia-y-misticismo-vikingoen-roma-de-cuaron/

Valdés, M. (13 de diciembre del 2018). After Gravity, Alfonso Cuarón Had His Pick of Directing Blockbusters. Instead, He Went Home to Make Roma. The New York Times Magazine. https://www.nytimes.com/2018/12/13/magazine/alfonsocuaron-roma-mexico-netflix.html

Weintraub, A. (24 de febrero del 2019). The Blanch and White Art Film in the Age of its Digital Distribution. Post45. https://post45.org/2019/02/the-black-and-white-art-filmin-the-age-of-its-digital-distribution/ 